\title{
MUJERES EN BICICLETA. Imaginarios, prácticas y construcción social del entorno en la ciudad de Sevilla
}

\author{
Elena HUERTA; Cristina GÁLVEZ \\ Grupo de Investigación Social y Acción Participativa, UPO (España) \\ elena_h_rl@hotmail.com, mcrisgalvez@gmail.com
}

WOMEN CYCLING. Collective imaginary, practices and social construction of the enviroment in Seville

Resumen: El uso de la bicicleta como medio de transporte urbano está demostrando poseer un importante potencial para modificar algunas piezas fundamentales de un modelo de movilidad insostenible pero aún dominante. Sin embargo y a pesar de su creciente presencia en el paisaje urbano, desplazarse en bicicleta no termina de ser la mejor opción para determinados grupos o perfiles de población. La ciudad de Sevilla se presenta como un caso interesante para abordar esta cuestión. En muy pocos años y tras la implantación de distintas medidas de fomento, entre las que resultó clave la ejecución de la red de vías ciclistas, se produjo un importante incremento en el número de usuarios/as de la bicicleta, al tiempo que se han ido desplegando una serie de procesos socioculturales asociados a la integración de la misma en la ciudad. Sin embargo, a pesar del boom ciclista, solo en torno al 35\% de quienes la utilizan para sus desplazamientos cotidianos son mujeres. Si bien en los últimos años se está produciendo un incremento de este colectivo, encontramos importantes contrastes en base a determinados perfiles, edades, horarios y zonas de la ciudad.

\footnotetext{
Abstract: The use of the bicycle as urban transport is proving to have a significant potential to change some fundamental parts of an unsustainable, but still dominant, mobility model. Despite its increasing presence in the cityscape, commuting by bycicle does not seem to be the best choice for certain population groups. Seville is presented as an interesting case to address this issue. In a few years and after the implementation of various promotion measures, among which the cycle lanes network was key, there was a sharp increase in the number of commuter cyclists, whilst a range of sociocultural processes associated with the integration of urban cycling have been deployed. However, despite the sevillian cycling boom, only about $35 \%$ of those who use it for their daily travels are women. Even though there was an increase of this group in the last years, we found significant contrasts based on certain profiles, ages, times and areas of the city.
}

Palabras clave: Representaciones sociales. Espacio urbano. Mujeres. Ciclismo urbano. Movilidad sostenible. Social representation. Urban spaces. Female cycling. Sustainable mobility. 


\section{Introducción}

Los sistemas de movilidad y transporte han sido elementos clave en la configuración de toda ciudad. Responden a nuestra organización socioeconómica e inciden sobre las capacidades de acceso a bienes, servicios y espacios públicos. Las pautas de movilidad de mujeres y hombres son diferentes, pues distintas son sus realidades y posibilidades de desplazamiento, lo que ha ido marcando de forma diferenciada los medios de transporte utilizados, así como las maneras de transitar y de habitar la ciudad.

A lo largo del siglo XX el automóvil ha ido ocupando un papel central en nuestras sociedades, de forma que alrededor de él se ordena, se regula y se ocupa el espacio público. Los privilegios otorgados a este vehículo tienen un marcado componente de género, pues han sido los hombres quienes han gozado de la legitimación social para acceder al mismo antes que las mujeres. Actualmente siguen existiendo más hombres conductores que mujeres y, aunque esta desproporción se ha reducido en las últimas dos décadas, ellas siguen siendo las principales usuarias del transporte público y realizan buena parte de los desplazamientos a pie. Los hombres tienden a desplazarse más lejos, más rápido y sus desplazamientos son, en general más uniformes y lineales, mientras que las mujeres realizan desplazamientos menores pero más heterogéneos, realizando más paradas en cada viaje y combinando más medios de transporte (Illárraz,2006; Calvo, 2013; Castilla; y otros, 2013).

Este modelo de movilidad tiene importantes consecuencias socioecológicas (elevados índices de contaminación, accidentes, estrés, ocupación del espacio público, etc.), lo que está llevando a la búsqueda de fórmulas alternativas más sostenibles, que implican no solo el uso de medios de transporte más "limpios", sino también el cuestionamiento del modelo de ciudad hegemónico.

El creciente uso de la bicicleta como medio de transporte - señalado por los/as usuarios/ as como excepcionalmente práctico en los desplazamientos urbanos- está demostrando ser una opción con potencial para modificar ciertos elementos clave de las actuales dinámicas de movilidad en una ciudad como Sevilla.

Sin embargo, partimos de una importante desproporción en el uso de la bicicleta en función del género. En el caso de Sevilla, tan solo entre el 32 y el $35 \%$ de quienes la usan como medio de transporte son mujeres (Marqués; y otros, 2012). El mismo fenómeno se reproduce en otras ciudades en las que se están desarrollando procesos de integración de la bicicleta urbana; mientras que en lugares donde este proceso está más consolidado, estas proporciones tienden a equilibrarse (Garrard; y otras, 2012). Varios son los estudios que intentan explicar estas desproporciones en base a la conjunción de diferentes variables socioculturales y ambientales (Bonham y Wilson, 2012; Garrard; y otras 2012; Heesch; y otras, 2012, entre otros), lo que nos lleva a reflexionar, en última instancia, sobre la importancia del entorno urbano y su relación con los procesos socioculturales asociados a su integración como medio de transporte.

El trabajo que presentamos aquí es fruto de una inmersión etnográfica llevada a cabo en el marco del proyecto "Movilidad sostenible en Andalucía: prácticas y discursos en el uso de la bicicleta" (G-GI3001/IDIX), desarrollado durante 2014 y 2015 por un equipo de investigadores/as de la Universidad Pablo de Olavide y financiada por la Consejería de Fomento y Vivienda de la Junta de Andalucía. Cádiz, Córdoba, Granada, Málaga y Sevilla fueron los casos principales de estudio en los que, además de la etnografía se desarrollaron varios grupos de discusión (seis en el caso de Sevilla) y dos foros participativos en cada ciudad.

El caso de Sevilla se confeccionó a partir de 57 entrevistas a diferentes agentes (representantes de asociaciones y de formaciones políticas, técnicos/as de la administración pública, empresarios/as, usuarios/as y no usuarios/as de la bicicleta), junto a un buen nú- 
mero de conversaciones y un trabajo de observación participante continuo. La atención a la diferenciación de usos y discursos en base al género se percibió, desde los inicios, como una variable clave a la hora de analizar la integración de la bicicleta en las distintas ciudades andaluzas.

Basándonos en los resultados obtenidos, pretendemos mostrar cómo aquellos aspectos que tienen que ver con las percepciones y representaciones existentes en torno al uso de la bicicleta por parte de las mujeres influyen en la forma en que la utilizan y en su acceso real a la misma. Para ello, hemos dedicado una primera parte del texto a plantear ciertas cuestiones teóricas sobre construcción social del espacio, movilidad y percepciones sociales desde una perspectiva de género, así como a un breve recorrido por algunas de las imágenes sociales más relevantes sobre mujeres y bicicleta desde la aparición de esta hasta nuestros días. En la segunda parte abordamos el caso sevillano a través de la caracterización de las ciclistas que circulan por sus calles y la evolución de las percepciones sociales en torno a las mismas. Por último planteamos algunas cuestiones que consideramos que pueden ser interesantes de cara a futuras investigaciones e intervenciones de fomento del ciclismo urbano de una forma equitativa.

\section{De espacios transitados, representados y soñados}

La concepción de espacio urbano como espacio que se construye a partir de las acciones de los individuos que lo ocupan es ya un clásico en los estudios de antropología urbana. Desde que Lefebvre expusiera su tesis sobre una "producción social del espacio" (2013) han sido muchos los autores (Simmel, 1986; Joseph, 1988; De Certeau, 2000 o Delgado, 2007, entre otros) que han explorado este enfoque y se han interesado por las interrelaciones que conforman las ciudades de la sobremodernidad.

Como espacio construido y recreado por sus ocupantes, el espacio urbano es un espacio emergente formado a partir de la acción de los usuarios, que lo reinterpretan a partir de las formas en que acceden y hacen uso del mismo (Delgado, 2007). Esta actividad es la que dota a los espacios urbanos de su carácter, independientemente de las directrices con los que han sido diseñados. Aunque el proyectista intenta conceptualizar la ciudad a partir de categorías, son los "practicantes de la ciudad quienes se desentienden de las directrices diseñadas (...) y se abandonan a apropiaciones efímeras y transversales" (Delgado, 2007: 15).

En ellas, la movilidad, como cualidad inherente a la construcción del espacio urbano, resulta medular (Jirón, 2007). En la medida en que el espacio urbano se ha ido transformando en una mera función del movimiento (Sennet, 1997) la movilidad ha ido cobrando protagonismo como fenómeno social. Según Lange la movilidad urbana, "amplía y diversifica los ámbitos de experiencia cultural que sus habitantes tienen de la ciudad y sus conciudadanos" (Lange, 2011: 92-93).

Pero, ¿cómo nos movemos? ¿Cuáles son y de dónde surgen las prácticas que propician ese espacio urbano siempre en tránsito? Para De Certeau, existen reglas explícitas y principios implícitos que marcan por igual las prácticas que dan forma a la ciudad (De Certeau, 2000: 62). Las primeras - el espacio proyectado - señalan los espacios restringidos y los aceptados, las normativas sobre la manera de circular según qué tránsito y vehículo, mientras que los segundos se asocian a lo que "resulta apropiado" o no, y están directamente relacionados con lo que García Canclini define como "imaginarios urbanos" (2001), es decir, representaciones sociales sobre las características del espacio urbano y las conductas adecuadas en él.

Las travesías cotidianas son los lugares en los que se elaboran y viven dichos imaginarios. Explorarlos nos resulta, por tanto, necesario para comprender cómo se articula la construcción del espacio desde las representaciones sociales y viceversa.

Cuando hablamos de representaciones sociales, hablamos inevitablemente de percep- 
ciones. Unas y otras resultan inseparables entre sí, ya que la percepción, además de contar con una base física, es aprendida dentro de un grupo cultural que define su uso (Rodaway en Spinney, 2007). Para convertirse en representaciones, estas percepciones se comparten y se construyen "a través de significantes verbales y visuales que sirven de puente para el entendimiento mutuo" (Ingold, 2000: 158). Las imágenes publicitarias, la tradición histórica y los discursos científico-técnicos de cada época, entre otros, fijan dichas representaciones en el acervo del conocimiento colectivo e influyen en las prácticas que conforman el espacio urbano. Por supuesto, se trata de una relación recursiva: las prácticas sociales son la plasmación de un conjunto de representaciones colectivas y, al mismo tiempo, las generadoras de estas, del mismo modo que el espacio urbano es receptáculo pero también generador de dichas representaciones.

Al mismo tiempo, en este espacio de tránsito se producen, de forma espontánea, constantes negociaciones de los códigos pactados entre los usuarios (Peña, 2003), que definen los modos de estar y moverse en el mismo. Para los actores de la vida pública la meta es "resultar adecuados, afirmarse, hacerse aceptables" (Delgado, 2007: 37). Y es que entrar en el escenario social de lo urbano implica, ante todo, aceptar someterse a las miradas de los otros (Delgado, 2007).

Pero no todos los actores ocupan la misma posición en dicha negociación, del mismo modo que no todos tienen la misma experiencia del entorno que habitan. Existe una heterogeneidad de actores y acciones que otorga a lo urbano su carácter caleidoscópico y plural. La experiencia urbana nunca es neutra u homogénea: existen condicionantes que marcarán de forma diferenciada la vivencia de la misma. El género es una de las variables que condicionan de manera inequívoca las prácticas urbanas, y en concreto las formas de movilidad (Morillo, 2014).

La subida de las mujeres a la bicicleta constituyó en su momento una transgresión de los códigos socialmente pactados hasta el momento y una sacudida de las representaciones vigentes. En contra de lo socialmente estipulado, un sector de las ocupantes del espacio urbano adoptó una nueva práctica, otra forma de desplazarse y estar en el espacio público. Esa práctica fue posible gracias a la existencia de ciertos imaginarios sociales emergentes que apoyaron la incorporación de la mujer al ciclismo, y a pesar de otros que la obstaculizaron. A día de hoy, los imaginarios sobre mujer y bicicleta, caracterizados por estrategias, adaptaciones o rebeliones de las propias mujeres que se desplazan en bici, siguen marcando, como veremos, la forma y la frecuencia en que estas se suben a una bicicleta y pedalean por la ciudad. Se crea así un escenario mucho más complejo y diverso, en el que las nuevas y viejas percepciones sobre mujeres y bicicletas se superponen y entretejen.

\section{Mujeres y bicicletas: nuevas y viejas imágenes}

La asociación entre mujeres y bicicletas ha constituido desde sus inicios un binomio llamativo y recurrente, y en no pocos casos problemático, para las sociedades occidentales. Dichas representaciones, alentadas en gran medida por los medios de comunicación, han influido en la concepción que la sociedad tiene de lo que significa montar en bicicleta siendo mujer, lo que resulta apropiado hacer y lo que no; lo que las mujeres, como mujeres, están capacitadas para realizar y lo que escapa a sus posibilidades. Los imaginarios sobre mujeres en bicicleta han dictaminado el tipo de indumentaria, conducción y espacio al que estas pueden o no tener acceso. Así, las prácticas desarrolladas por las mujeres a la hora de desplazarse y las de los hombres a la hora de relacionarse con estas, han bebido de toda una serie de discursos que, en mayor o menor medida, han permeado las distintas épocas y estratos sociales. En ningún caso se ha tratado de una respuesta unívoca y homogénea a dichas representaciones, sino más bien de distintas estrategias — de adaptación o resistencia— que han ido conformando a su vez nuevas imágenes superpuestas a las anteriores. 
Las imágenes asociadas a la mujer que pedalea han sido recurrentes en los medios de comunicación prácticamente desde la última década del siglo XIX. No son pocos los artistas gráficos que se han valido del icono mujer/bicicleta para publicitar productos que no necesariamente tienen que ver con el elemento que utilizan como reclamo, reforzando la idea de que la mujer en bici es, ante todo, un símbolo o un fetiche, además de una consumidora cuya acción es vital para el mantenimiento de un mercado siempre necesitado de expansión. Pero, sobre todo, nos muestran que la mujer en bicicleta ha estado y sigue estando sujeta a determinadas atenciones, restricciones e interpretaciones por parte de la sociedad a la que pertenece. "Moverse en un cuerpo de mujer", escribe Sarah Goodyear "significa estar expuesta a un conjunto de expectativas sociales, restricciones y juicios sobre cómo vestir y comportarse. Pon ese cuerpo sobre una bicicleta y las cosas se complican más aún" (Citylab, 2014) $)^{1}$.

\section{Las pioneras a dos ruedas}

En Europa y Norteamérica, la aparición de la bici segura supuso la incorporación de las mujeres al mundo ciclista (Aronson, 1952; Mackintosh y Norcliffe, 2007; Barrera, 2014), algo que causó no poco revuelo en la conservadora sociedad del momento. Las mujeres que a finales del XIX se subieron con entusiasmo a las dos ruedas provocaron una auténtica revolución social que tenía que ver con la lucha por la emancipación femenina. Era el momento en que emergía la New Woman (Simpson, 2001), una mujer que quería vestir y comportarse de manera distinta, conquistar nuevos espacios físicos y simbólicos, y para quien la bicicleta era uno de los principales exponentes de independencia y libertad.

Pero esta libertad tuvo rápidamente nuevas interpretaciones. La bicicleta fue vista por un amplio sector de la sociedad como un peligro manifiesto para el orden establecido (Hendrick, 2016) ${ }^{2}$. El cambio de vestuario que su uso propiciaba (los pantalones bombachos, la ausencia de corpiño) y la ampliación del espacio en el que estas se desenvolvían, fueron vistos como una amenaza al orden moral de la conservadora sociedad victoriana, que temía que las hasta entonces bien vigiladas damas pudieran ir y venir a su antojo, desatender el hogar y abandonar el recato de atuendo y comportamiento que debía lucir toda señora o señorita respetable. Enseguida surgieron discursos altamente hostiles hacia las mujeres que montaban en bicicleta que quedan reflejados en periódicos de la época y dan cuenta de la relación que se estableció entre este hecho y una conducta inapropiada (Zubiaurre, 2007): la ciclista era equiparada a una mujer de moral relajada, o bien a una mujer "masculinizada" que pretendía imitar a los hombres (Simpson, 2001), imágenes ambas con fuerte carga peyorativa.

El discurso médico contribuyó también a esta imagen de la ciclista como "mujer perdida" a través de solapados juicios morales en sus diagnósticos. La práctica ciclista se asoció al aumento de la masturbación femenina (Simpson, 2001) y se extendió la idea de que pedalear durante periodos prolongados podía alterar la frágil salud de las mujeres, llegando incluso a diagnosticarse la enfermedad "cara de bicicleta" (Aronson, 1952).

\section{De la mujer liberada a la nueva burguesa}

Precisamente en respuesta a las imágenes peyorativas que se extendían sobre las mujeres ciclistas, muchas pusieron especial énfasis en adoptar conductas que desmintieran los supuestos de irrespetabilidad a los que eran sometidas. El reto para ellas era el de montar en bicicleta y seguir siendo decentes (Simpson, 2001), para lo que tenían que desarrollar estrategias que demostraran de forma inequívoca su "inocencia". Así surgieron toda una serie de decálogos para las mujeres que quisieran subirse a las dos ruedas, como los de Erskine (1897) o Willard (1895), con recomendaciones tales como transitar por espacios iluminados

1 En http://www.citylab.com/commute/2014/04/there-such-thing-feminine-way-ride-bike/8886/

2 En http://xroads.virginia.edu/ ug02/hendrick/women.html 


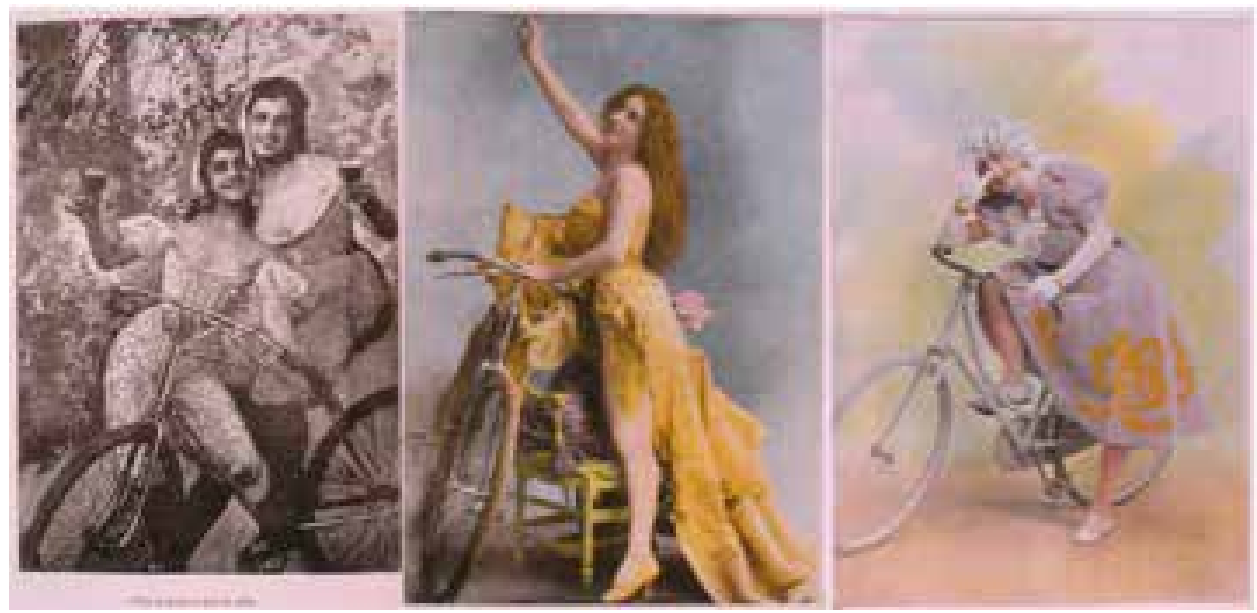

Figura 1. Ilustraciones en Vida Galante, 1899, 1903 y 1903 respectivamente (de izquierda a derecha). Fuente: Zubiaurre, 2010.

y fácilmente accesibles, hacerlo en compañía, pedalear de manera contenida y en ningún caso a grandes velocidades; llevar una falda que poder ponerse encima de los pantalones una vez alcanzado el lugar de destino... Si no se puede evitar que la mujer se suba a la bicicleta, es entonces necesario transmitir una imagen de la ciclista que en ningún caso ponga en peligro los sacrosantos valores de la familia burguesa. La bicicleta se convierte en un objeto de moda y de estatus (no olvidemos su alto precio, que la convertía en un bien solo asequible para las clases acomodadas) que puede y debe lucirse en apacibles paseos por parques y jardines y otras actividades de ocio en las que las mujeres salen acompañadas de sus maridos y protectores (Mackintosh y Norcliffe, 2007), y del que se excluye el ciclismo utilitario.

\section{La erotización de la mujer a dos ruedas}

De forma paralela a la representación de la mujer en bicicleta como una mujer poco deseable desde el punto de vista social, aparece la de mujer deseada, cuya erotización se vehiculiza a través de la asociación de lo supuestamente "masculino" (el metal, lo duro, la velocidad) con las poses y atuendos de lo "femenino" (la turgencia, la pasividad, lo blando). Zubiaurre (2007) documenta la amplia producción de imágenes eróticas en la España de fin del siglo XIX en las que aparecen mujeres junto a bicicletas en poses seductoras o insinuantes. En ningún caso estas imágenes sugieren una idea de mujer que utilice la bici como medio de transporte, sino que los atuendos, las posturas y los escenarios nos hablan de mujeres que quedan siempre relegadas al espacio del tocador (Zubiaurre, 2007).

$\mathrm{Y}$ es que, a la mujer que pedalea de forma modesta y recatada, bien tapada y a la luz del día, se superpone el fantasma de esa otra que, con el pelo al viento y las piernas al descubierto, escapa a todo control social e incurre en actitudes claramente censurables pero también provocadoras del deseo masculino. Para domarla, nada mejor que confinarla a un espacio de inmovilismo y seducción.

\section{La bici, el complemento de moda}

A partir de los años cuarenta asistimos a una "feminización" recurrente de la bicicleta en la publicidad y en el cine. Actrices de Hollywood aparecen posando en bicicleta y traje de baño con amplias sonrisas. La bicicleta, además, se ha ido adaptando a los gustos y estéticas 


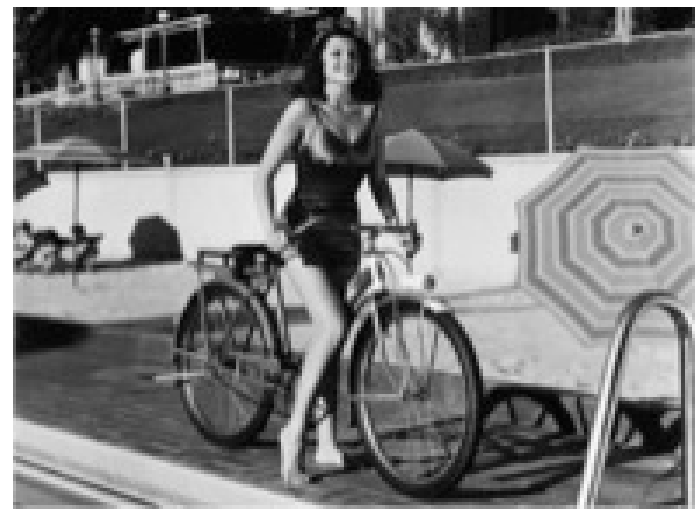

Figura 2. Rita Hayworth en la piscina del Beverly Hills Hotel, Fuente: VOGUE, 2012.

femeninas. En plena España franquista aparece el libro "La mujer y la bicicleta", donde se apunta una razón de "similitud" entre las formas redondeadas y la "frágil naturaleza" de una y otra para explicar la predilección de las mujeres por este vehículo (Marsillach, 1944) 3 . Se considera que la bicicleta es, en la mujer, un "feliz complemento" de la indumentaria y una prolongación de la personalidad, una parte más de la estampa femenina; pero eso sí, de una estampa femenina de clase alta que utiliza la bici más por estética que por utilidad.

En cualquier caso, si la bicicleta podía ser vista como un curioso complemento del encanto femenino, esta quedaba reservada para las artistas o las mujeres de la burguesía. Las clases proletarias y el mundo rural andaluz seguían considerando su uso poco apropiado para el recato femenino. Aunque estaba muy extendida como medio de transporte entre las clases obreras, se trataba de un dominio prácticamente exclusivo de los varones. La mujer podía viajar en bicicleta "de paquete" con su marido o su novio, sentada de lado sobre la barra con las piernas recogidas, estampa frecuente en los pueblos de toda España hasta bien entrados los años sesenta.

A partir de los 60 la bicicleta fue perdiendo protagonismo en Andalucía como medio de desplazamiento entre las clases menos pudientes y como elemento de divertimento y deseabilidad social entre las más adineradas. Lo práctico, lo moderno y lo cool era el coche. La bicicleta dejó de ser el vehículo de la transgresión, la eficacia o la libertad para convertirse en un mero juguete que, además, comenzaba a ser cada vez más peligroso en un entorno rápidamente saturado de vehículos motorizados. Quedó así relegada al ámbito deportivo, feudo altamente masculinizado en el que con frecuencia se asume que montar en bici requiere de una serie de cualidades "masculinas" como son la velocidad, la fuerza física o incluso la agresividad.

\section{El movimiento Cycle Chic}

Uno de los movimientos ciclistas más discutidos y emulados en la actualidad es el Cycle Chic, corriente que surge en Copenhague gracias a una fotografía tomada en el 2006 por Colville-Andersen en la que aparece una ciclista joven y elegantemente vestida pero que, claramente, hace un uso real y cotidiano de la bicicleta. La idea de aunar movilidad y estilo es la que subyace al decálogo del movimiento, que se ha extendido por numerosas ciudades y calado en los imaginarios sociales del ciclismo urbano europeo. En Madrid y Barcelona ya existen movimientos Cycle Chic, y no podemos obviar su influencia en tiendas y talleres ciclistas, así como en las formas de subirse a una bicicleta por parte de muchas mujeres y hombres.

3 En http://www.terra.org/categorias/blog-de-un-ecologista/la-mujer-y-la-bicicleta 
La imagen Cycle Chic toma, por una parte, el discurso de elegancia de la burguesía y, por otro - aunque muy lejos del activismo - las reivindicaciones de los movimientos ciclistas urbanos. Sus defensores transmiten la idea de que se puede ir en bicicleta sin renunciar al estilo propio - estilo que tiene mucho que ver con los dictados de la moda imperante- . La mujer Cycle Chic es una mujer independiente, que va en bici a donde quiere y como le place sin renunciar a una imagen basada en buena medida en la indumentaria, el tipo de bicicleta que usa y una forma de conducción donde priman la "gracia, elegancia y dignidad"4. Esto, que ha sido visto por muchos como una objetivización más de las mujeres, forma sin embargo parte de las reivindicaciones de muchas de ellas: poder desplazarse de la manera en que elijan sin tener que renunciar a su aspecto habitual. Así, el uso de faldas o tacones sobre la bici es considerado a día de hoy una conquista de la libertad femenina más que una imposición de la moda.

Por otro lado, son muchas las mujeres que están reinventando los imaginarios sociales a partir de discursos en los que el cuerpo es valorado por las habilidades y posibilidades que desarrolla y no tanto por la apariencia que presenta ${ }^{5}$, pasando así de ser un objeto susceptible del juicio ajeno - estético o moral - a una herramienta válida para relacionarse con el ambiente.

A continuación veremos en qué medida este tipo de imaginarios están presentes en las prácticas y discursos de las ciclistas sevillanas y cómo han ido tejiéndose con los procesos de integración de la bicicleta vividos en los últimos diez años.

\section{El caso de Sevilla}

En la capital andaluza habitan cerca de 700.000 personas, una cifra que casi se duplica si contabilizamos la población de los 45 municipios del área metropolitana de Sevilla. Como en muchas otras ciudades, las dinámicas de movilidad y el uso del vehículo privado se han intensificado en las últimas décadas:

"[...] en el plazo de 17 años (1990-2007) el número de viajes ha aumentado casi un 80\% [...] todo este incremento se ha basado en el ascenso paralelo de la utilización del coche que llegó en 2007, a absorber el 73,6\% de los viajes mecanizados [...]" (Calvo, 2013: 86)

En la primera década de los 2000 comenzamos a vislumbrar ciertas tendencias de cambio en las políticas de movilidad y gestión de ciertos espacios urbanos. La ciudad de Sevilla constituye un caso sin precedentes en la integración de la bicicleta como medio de transporte. Su singularidad gira en torno a la intensidad con la que se produjo el incremento y diversificación de sus usuarios/as (Huerta y Hernández, 2015). Inmediatamente después de la ejecución de la red de vías ciclistas y la implantación del sistema de bicicletas públicas, SEVICI (a partir del 2007), miles de personas comenzaron a "sacar las bicicletas de los trasteros" y a utilizarla como vehículo, lo que supuso que, entre 2006 y 2009, la bicicleta pasara de un $0,6 \%$ a un $6 \%$ en la cuota de reparto modal de los viajes mecanizados (Ayto. Sevilla, 2010). En el 2013 esta cifra se sitúa en torno a un 9\% (Marqués; y otros, 2014).

\section{Mujeres y bicis en Sevilla. Breve caracterización}

Con el boom ciclista sevillano, se han ido desplegando determinados procesos socioculturales que, entre otras cuestiones, han pasado por resignificaciones de la propia bicicleta y de quienes la utilizan. La bicicleta forma parte ya de los paisajes cotidianos de la ciudad,

4 Según el decálogo Cycle Chic (en http://madridcyclechic.blogspot.com.es/p/madrid-cycle-chic-manifesto_22. html).

5 En http://www.citylab.com/commute/2014/04/there-such-thing-feminine-way-ride-bike/8886/

6 Un informe recientemente publicado confirma una tendencia a la baja durante los últimos años. La falta de mantenimiento y mejora de la infraestructura, así como la ausencia de medidas de fomento, se apuntan como principales hipótesis para explicar este descenso (Marqués; y otros, 2016). 


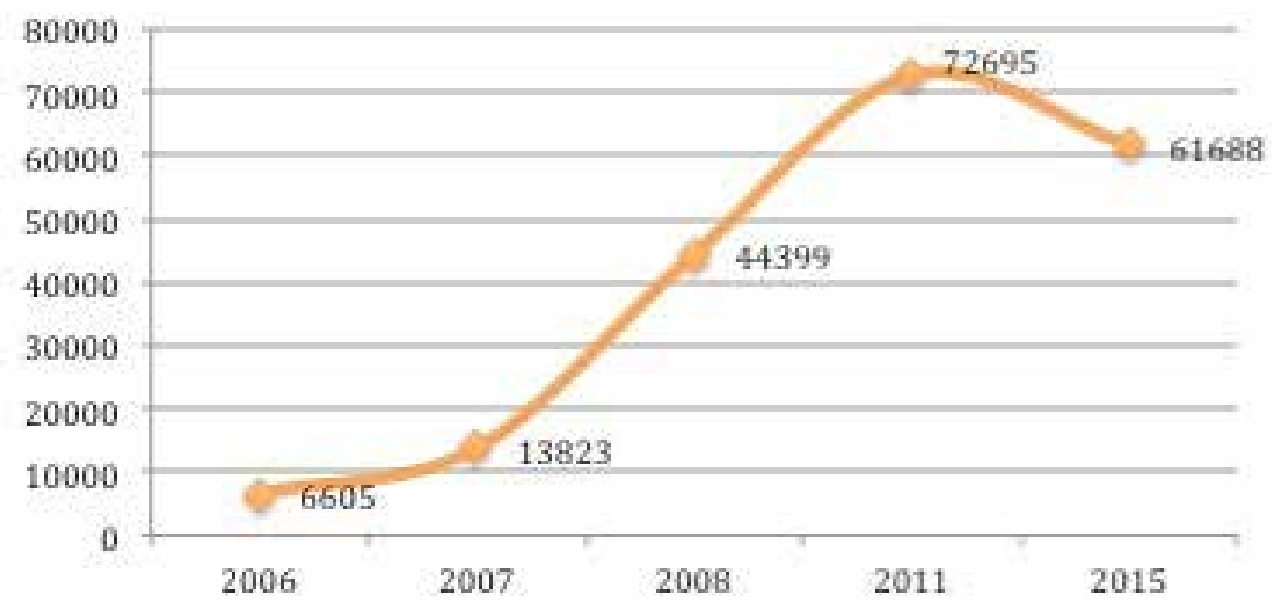

Figura 3. Evolución del número de usuarios/as de la bicicleta en Sevilla en día laborable. Elaboración propia a partir de Ayto. de Sevilla (2006, 2007 y 2008) y Marqués; y otros (2012, 2014 y 2016).

se ha convertido en un elemento polisémico capaz de transmitir una gran pluralidad de mensajes, interviene en las formas de experimentar y representar la ciudad, así como en los tiempos y espacios en los que se desarrollan las sociabilidades cotidianas.

Sin embargo, como ocurre en muchos otros lugares, la mayor parte de quienes la utilizan para sus desplazamientos cotidianos siguen siendo hombres ${ }^{7}$. En Sevilla, esta desproporción se sitúa en torno al 32-35\% de mujeres, frente a un 65-68\% de hombres (Marqués; y otros, 2012).

Estas cifras nos hablan sobre la relación existente entre el grado de integración de la bicicleta y la proporción de uso en base al género (Garrard; y otras, 2012). No obstante, comprender cómo se está desarrollando este proceso y su vinculación con los imaginarios sociales en torno al uso de la bicicleta por parte de las mujeres requiere de un enfoque cualitativo que atienda a la diversificación de perfiles ciclistas, menor que en el caso de los hombres, y a la importancia de determinadas variables: las variaciones de uso en diferentes zonas de la ciudad, franjas horarias o edades resultan especialmente relevantes a la hora de caracterizar las prácticas ciclista de las mujeres en Sevilla.

Según los datos que ofrecen Marqués y colaboradores (2012) y lo registrado en nuestras propias observaciones, el uso de la bicicleta entre las mujeres se concentra entre los 25 y los 55 años, mientras que en el caso de los hombres esta horquilla se amplía por ambos extremos. Hay que tener en cuenta, sin embargo, que las horas punta son momentos en los que esta desproporción suele disminuir.

La presencia de mujeres en bici también se ve influida por la zona de la ciudad en la que nos encontremos. El centro y sus principales vías de acceso son zonas de gran afluencia ciclista en las que, además, las desproporciones de uso en base al género disminuyen, situándose en torno al $40 \%$ de usuarias en horas punta de días laborables (Ayto. de Sevilla, 2010 y 2013, Huerta y Hernández, 2015 y Marqués; y otros, 2016).

En el caso del casco histórico, la propia configuración urbanística, las estrechas calles, la

7 Australia, Reino Unido o Estados Unidos son algunos ejemplos en los que las ciclistas urbanas no superan el $30 \%$, mientras que en lugares donde la bicicleta utilitaria está más normalizada, estos índices suelen tender a equilibrarse: Suecia, Finlandia o Alemania se sitúan en torno al $50 \%$ y en países como Holanda o Dinamarca, son más las mujeres que se trasladan en bicicleta (Garrard; y otras, 2012). 
inexistencia de vías ciclistas, los sentidos únicos de circulación, las zonas peatonales y las propias dinámicas socio-económicas conforman un espacio de características particulares para el uso de la bicicleta. La zona norte del casco histórico constituye un ejemplo singular de cómo esta ha pasado a formar parte de la vida cotidiana. El trazado urbano, junto a las tradicionales dinámicas peatonales, obliga a una convivencia no regulada por semáforos ni por espacios segmentados que ha favorecido un tráfico más calmado que en otras zonas. Pero además, la propia historia de estos barrios, la importante presencia de una población relativamente joven, ciertas dinámicas socio-económicas (vinculadas principalmente al pequeño comercio y a la hostelería), así como con un importante tejido social en lo que refiere a iniciativas y movimientos sociales, favorece la existencia de ciertas singularidades en torno a "la vida de barrio" de esta zona de la ciudad; lo que ha influido, sin duda, en que la bicicleta se integre en las dinámicas colectivas e incluso pase a formar parte de los elementos simbólicos e identitarios de estos barrios. Madres y padres desplazándose con sus hijos/as al colegio o bicicletas apiladas en cualquier esquina de una plaza o de algún bar son estampas cotidianas no tan frecuentes en otros barrios. También esta zona acoge una mayor concentración de tiendas y talleres ciclistas, lo que además de indicar un mayor uso, favorece la visibilización social de la bicicleta en los espacios públicos. De hecho, la existencia de talleres cercanos y accesibles juega un papel importante en su incorporación a las hábitos cotidianos de movilidad. Algunas usuarias residentes en barrios extra-muros han expresado cómo no tener un taller cercano para poner a punto la bicicleta, o para arreglar un pinchazo sobre la marcha, llega a desincentivar su uso.

Aunque la red de vías ciclistas llega prácticamente a todos los barrios de la ciudad, el uso de la bicicleta decrece al alejarnos del centro y también lo hace el índice de mujeres al pedal (Marqués; y otros, 2012 y 2016). Estos datos refuerzan lo registrado en nuestras observaciones y entrevistas, que apuntan a una menor presencia de la bicicleta en estas zonas y nos permiten identificar esta correlación entre la intensidad de su uso y la participación de las mujeres en este modo de transporte.

El perfil mayoritario de las ciclistas urbanas de Sevilla está compuesto por mujeres jóvenes, entre 30 y 45 años, con estudios, mayoritariamente con empleo, algunas con hijos/ as a su cargo y que, pudiendo residir dentro o fuera del casco histórico, lo frecuentan por diversos motivos. El uso principal que hacen de la bicicleta es utilitario y, si bien algunas ya la utilizaban antes de la red de vías ciclistas, la mayor parte de ellas ha comenzado a hacerlo cuando estas estuvieron operativas. Las entrevistas realizadas nos han permitido comprender los tipos y frecuencia de uso pero, sobre todo, el papel que tiene este vehículo en su cotidianeidad. Para muchas de ellas, la bicicleta se utiliza para todo: compras, ocio, trabajo, estudios, etc., bien sean desplazamientos a nivel de barrio u otros que requieran mayores distancias.

Otras mujeres han encontrado en la bicicleta una estupenda opción para integrar algo de ejercicio en sus desplazamientos cotidianos. Generalmente residentes en barrios externos al casco histórico, con edades superiores a las del perfil mayoritario y frecuentemente en compañía de otras mujeres, es bastante habitual encontrar estos usos mixtos que se dan en el propio carril-bici o en combinación con otros espacios de uso deportivo-recreativo. Parques, paseos y otros espacios verdes en distintas zonas de la ciudad se convierten así, durante muchas mañanas entresemana, en lugares transitados que se combinan en el mismo itinerario con otras actividades.

Sin duda, la existencia y características de las vías ciclistas de la ciudad han facilitado el incremento y diversificación de los/as ciclistas urbanos/as, pero también son otros los elementos que han hecho que muchos/as se animen a desplazarse a dos ruedas. El propio efecto contagio, la novedad y la singular manera en la que la bici se está inscribiendo en la cotidianidad de la ciudad, junto con las características socio-espaciales del entorno por el que se circula, son elementos que han jugado un papel importante a la hora de optar por la 
bici como medio de locomoción. Muchas mujeres la han ido incorporando de forma progresiva y, aunque aún encuentran condicionantes que limitan su uso, la bicicleta no es ya un objeto ajeno a su cotidianeidad.

La mayor parte de las entrevistadas aprendieron a montar en bici a edades tempranas, pero también hemos recogido testimonios de mujeres que lo han hecho en edad adulta, $\mathrm{y}$ otras que no han aprendido o que aprendieron pero no se sienten capaces de utilizarla para desplazarse. No saber montar en bicicleta o saber pero no tener la confianza para usarla con autonomía es un hecho que se acentúa notablemente en el caso de las mujeres, y no es hasta que se produce el boom ciclista sevillano cuando esta realidad comienza a visibilizarse. En la muestra tomada para la realización del Barómetro Anual de la Bicicleta de 2011, se obtiene que el 86,1\% de quienes no saben ir en bici son mujeres (GESOP, 2011). De acuerdo con un estudio realizado en Sevilla sobre este tema, los principales motivos que explican por qué estas mujeres no aprendieron a montar giran en torno a la falta de acceso y fomento de su uso en edades tempranas y a la inseguridad y miedo percibidos para usarla como medio de transporte (Santa Cleta y Antropológicas 2013).

Tanto el tipo de uso y perfil mayoritario de mujeres ciclistas en Sevilla hasta aquí descrito, como las ausencias observadas, tienen mucho que ver, no solo con la infraestructura creada, sino con las representaciones y percepciones sociales existentes al respecto. La forma en que dichas percepciones se han transformado, superpuesto y adquirido nuevos significados en la ciudad es lo que ha permitido a muchas mujeres comenzar a desplazarse en bicicleta, y lo que todavía mantiene a otras, como veremos a continuación, en la incertidumbre.

\section{Percepciones sociales de las ciclistas urbanas en Sevilla: tránsitos y encrucijadas}

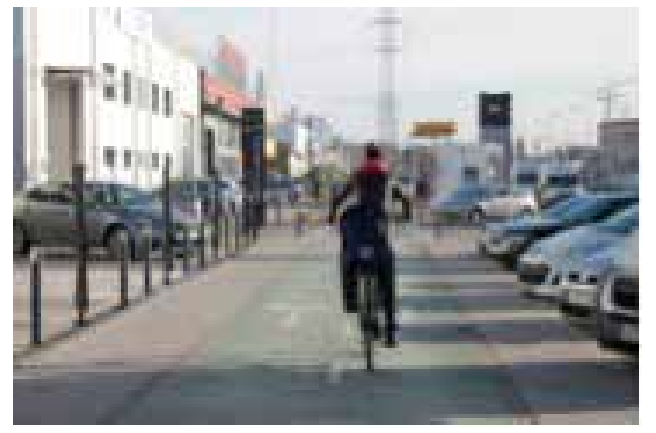

Figura 4. Usuarias de la bici en Sevilla, imagen propia.

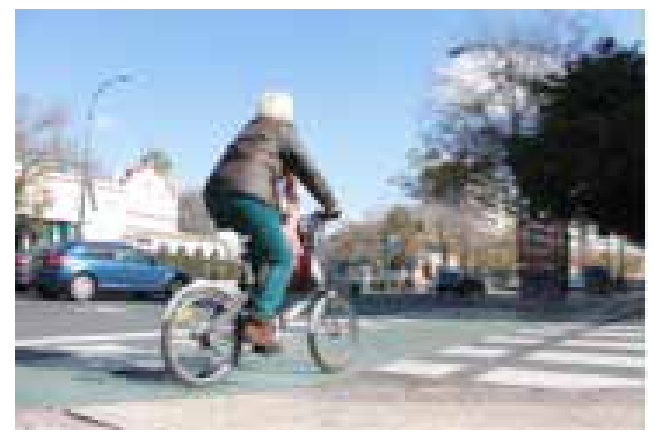

Figura 5. Usuarias de la bici en Sevilla, imagen propia. 
Como decimos, en esta última década se han producido intensos procesos de resignificación sobre la propia bicicleta y sobre quienes la utilizan; procesos que siguen en marcha en las esquinas y plazas de la ciudad.

Los inicios del proyecto de vías ciclistas no estuvieron exentos de dificultades y conflictos y no era extraño encontrar discursos hostiles hacia el mismo y hacia los/as propios/as usuarios/as. Especialmente relevantes resultaron los de ciertos medios de comunicación en los que quedaban patentes muchos de los estigmas en torno a la bici. Sin embargo, los discursos abiertamente contrarios al uso de la bici y a los beneficios que esta aporta a la ciudad son hoy prácticamente inexistentes.

¿De qué manera ha afectado este proceso a las mujeres que utilizan la bicicleta? Si bien hace cuarenta años podríamos hablar de un entorno en el que la bicicleta no era cosa de mujeres, en la actualidad, nos encontramos en un momento interesante en el que "viejas" y "nuevas" imágenes de la bici, la ciudad y las mujeres se combinan de forma compleja, dando lugar a un colorido mosaico de discursos e ideas sobre las mujeres al pedal. Una especie de encrucijada en la que, si bien el uso de la bicicleta se ha normalizado entre amplios sectores de la sociedad, persisten aún ciertas connotaciones que limitan las prácticas ciclistas de las mujeres.

Con su progresiva incorporación al ciclismo utilitario a partir del boom, se vienen produciendo cambios en las percepciones sobre las mujeres en bicicleta. En Sevilla, la imagen de una mujer en bicicleta se ha convertido en una especie de indicador social de su integración en la ciudad, casi a la altura de otras imágenes recurrentes registradas durante el trabajo de campo, como la del "ejecutivo en bicicleta". Mujeres, ejecutivos o niños/as en bici, se han convertido en una suerte de símbolo del cambio que ha experimentado la ciudad a raíz del auge ciclista, algo que hace apenas quince años era impensable para la mayoría.

Uno de los aspectos más interesantes lo encontramos en el sobredimensionamiento percibido en torno a la proporción de mujeres que se desplazan en bicicleta, percepción que también encontramos en otras ciudades andaluzas (Martín y Jordi, 2015; Moreno y Quintero, 2015; Gálvez y Del Campo, 2015; Sguiglia y Aix, 2015) y que nos muestra cómo una mujer en bicicleta sigue resultando más llamativa que un hombre.

"Lo que sí es cierto es que la mayoría de los usuarios son mujeres [...] la percepción [risas], será que me fijo más en las mujeres [...] a nivel general, [...] me da más percepción de ver más mujeres en bicicletas. Antes, muy pocos, lo que había es cuatro hombres." (Empresario de la bici).

Para quienes se desplazaban en bicicleta hace 15 años, pedalear entre coches y autobuses suponía muchas veces "jugarse el tipo". Las motivaciones eran diversas pero podríamos decir que para la población joven, donde se incluía la mayoría de las mujeres que circulaban en bici, existía en la práctica ciclista cierta lógica contestataria hacia a los modelos de ciudad imperantes. En el caso de las mujeres, la consideración de "extrañeza" y "minoría" que suscitaba de por sí el ciclismo urbano, se conjugaba con percepciones sociales ligadas al género, de forma que estas chicas que iban a dos ruedas por las calles de la ciudad se enfrentaban a menudo con comentarios, miradas y situaciones que reflejaban esta realidad. Algunas de estas veteranas señalan lo frecuente que era que se dirigieran a ellas de forma jocosa e incluso despectiva en algunos casos.

"Lo que era más coñazo era la gente, que me cantaban lo del verano azul, [...] para la gente no era nada normal que yo fuera en bici. [...] sobre todo también al ser tía, yo creo que a lo mejor con un tío no se meten tanto, pero yo llevaba siempre bicis de paseo, [...] eso era lo que hacía que más gente se cachondeara" (Usuaria de la bici). 
Testimonios de algunas madres que en esta época se desplazaban en bici con sus pequeños, relatan cómo en varias ocasiones experimentaron actitudes hostiles y reproches ante lo que parecía ser "una locura".

"Yo por ejemplo como mamá, he sido puteada en la calle, en el sentido de tratarme como delincuente, pues ¿cómo se me ocurría ir embarazada en la bicicleta o ir con un bebé en bicicleta?. H. no tanto, por ser varón [...]" (Usuaria de la bici).

Comentarios o miradas incómodas haciendo referencia a la postura que adoptamos en la bicicleta o testimonios en los que se hace referencia a lo "sexy" que resulta una mujer a dos ruedas, son ejemplos recogidos en otras ciudades andaluzas de menor uso ciclista, que en Sevilla parecen haberse suavizado con el auge ciclista. Esto no quiere decir que no existan: aún hoy detectamos actitudes que, sin ser tan explícitas, reflejan un trato desigual hacia las mujeres; por ejemplo a través de su consideración como "eternas principiantes" en el uso de la bici, bien sea urbano o deportivo.

Atendiendo a los entornos donde se produce la circulación ciclista, encontramos dos elementos fundamentales que limitan o facilitan la presencia de mujeres al pedal. Por una parte, las percepciones del riesgo y la seguridad de las propias mujeres, que han sido ampliamente abordadas y señaladas por diversos estudios, como una cuestión central que explica las diferencias de género en el uso de la bici (Emond; y otras, 2009; Garrard; y otras, 2012; Heesch; y otras, 2012).

De acuerdo con Garrard y colaboradoras (2012), las nociones de riesgo y seguridad, así como los elementos que intervienen en su construcción individual y social, son amplias y muchas de ellas quedan socialmente invisibilizadas: el hecho de que los cuerpos femeninos sean socialmente más observados y juzgados interviene, sin duda, en nuestros comportamientos, miedos, autopercepciones y vergüenzas (Garrard; y otras, 2012; Gálvez; y otras 2015). También se incluyen aquí las percepciones de lo que son conductas más o menos "responsables" en lo que se refiere, por ejemplo, a las mujeres que se desplazan en bici con niños/as pequeños/as (Garrard; y otras, 2012).

Paralelamente resulta necesario poner en relación lo anterior con aquellas otras percepciones que existen sobre estos espacios y sobre las maneras en que la bicicleta se inscribe en ellos. Por ejemplo, circular por la calzada implica no solo tener autoconfianza, sino también adquirir unas actitudes y destrezas acordes con las maneras en las que se circula o en las que se dice que se debe circular. La calzada es un espacio masculinizado que se refuerza como tal a partir de discursos y prácticas que reivindican comportamientos que simplemente no encajan, de forma general, con las lógicas de transitar de la mayor parte de las mujeres. Pero en la hostilidad del entorno percibida influyen además elementos como el humo, el ruido o las cualidades paisajísticas del recorrido; aspectos para los que las mujeres parecen poseer mayor sensibilidad (Heesch; y otras, 2012; Gálvez; y otras 2015).

La red de vías ciclistas ha favorecido la incorporación del colectivo femenino, no solo por vencer los condicionantes que suponen las percepciones de riesgo y seguridad; también porque es un espacio "propio" que permite una mayor flexibilidad para transitar al margen de las imposiciones de la calzada. En zonas donde no existen vías ciclistas, los recorridos de las mujeres se intensifican allí donde predominan el tráfico calmado y los desplazamientos no motorizados. Como hemos mencionado, la zona norte del casco histórico es un buen ejemplo de cómo la disposición, el diseño urbanístico y la normativa intervienen en las percepciones sobre el espacio, conjugándose con las propias prácticas, usos y significados sociales que se le atribuyen (Del Valle, 1997).

Esta idea de sentirse "cómoda" en el entorno por el que se circula es extrapolable a otros 
contextos y espacios que también consideramos ciclistas. El tejido asociativo, los espacios públicos de toma de decisiones o los comercios vinculados a la bicicleta juegan un papel importante en la generación de entornos más o menos atractivos para las mujeres. En ellos se plasman muchas de las imágenes del ciclismo urbano contemporáneo y, como ocurre en otros ámbitos, se trata de espacios en los que las mujeres suelen estar en minoría.

Nuestro trabajo de campo ha desvelado el interés que cobran estas imágenes y los procesos sociales ligados a su consumo, entendido este como un hecho cultural que forma parte de la "racionalidad integrativa y comunicativa de una sociedad" (García Canclini, 1995: 45). Imágenes sofisticadas, con notable influencia noreuropea, han ido calando en distintos espacios de la vida cotidiana. Así, para los responsables de tiendas y talleres, la atracción de clientas pasa por ofrecer una imagen del ciclismo urbano más amable y cercano a estas, en detrimento de estéticas deportivas cuya componente competitiva y épica resulta, generalmente, menos atractiva.

"No tenemos muchos deportistas [...] Tenemos mucha gente con bicis chatarra [...] y también muchas mujeres, más de lo normal, por el aspecto de la tienda. [...] porque muchas tiendas de bicicletas que son más deportivas creo que echan a la gente para atrás" (Responsable de tienda-taller).

Respecto a la vestimenta vemos que, cuanto más normalizado está el uso de la bici, más se normaliza también la indumentaria de las usuarias y menos son las limitaciones percibidas a este respecto. No obstante, hay que tener en cuenta cómo estas percepciones, se ven influidas por otras variables igualmente importantes como la edad o la posición social, el contexto cultural, etc. También el tipo de bicicleta utilizada resulta un elemento significativo en la elección de la indumentaria. En Sevilla, las bicicletas urbanas se han incrementado de forma notable en los últimos tiempos, ya que, a diferencia de la de montaña, facilita el uso de determinadas prendas.

La integración de la bicicleta conlleva además el desarrollo de una serie de procesos de apropiación, distinción y resignificación que se expresan en el consumo. Percepciones y representaciones ligadas al género forman parte de estos procesos, de forma que si bien el creciente uso de accesorios y complementos de la bici urbana favorecen distinciones de género, también sirven para vencerlas o modificar su sentido. Las cestas, por ejemplo, complemento asociado tradicionalmente a las mujeres y a una imagen recreativa de la bicicleta, han ido aumentando su presencia también entre los hombres. Así, las estéticas, condicionadas por estos procesos sociales de distinción, adquieren nuevos sentidos en base a la funcionalidad que obtienen a partir del uso.

Un último aspecto tiene que ver con la dimensión sensorial de la experiencia ciclista. Spinney señala la importancia de atender a estas cuestiones si realmente queremos comprender cómo y por qué la gente se desplaza (Spinney, 2011). Muchas de las mujeres han puesto de manifiesto las sensaciones de autonomía y libertad que les aporta moverse en bicicleta: poder llegar a cualquier sitio y a cualquier hora, hacer paradas en el mismo desplazamiento, las sociabilidades y otros aspectos sensoriales relacionados con la experiencia ciclista (olores, sonidos, temperatura, y otras sensaciones del ambiente) se vinculan con estos dos conceptos, ampliamente valorados por las entrevistadas. Así, la bicicleta se percibe como un medio de transporte particularmente flexible y que aporta autonomía a quien la usa.

\section{Conclusiones}

A lo largo del presente artículo hemos intentado mostrar cómo percepciones, prácticas y construcción social del espacio se relacionan en el ámbito de la movilidad ciclista, permi- 
tiéndonos profundizar en la comprensión de las desigualdades de género existentes en torno al uso de la bicicleta.

Entendemos que la presencia de mujeres que se desplazan habitualmente en bicicleta en las ciudades constituye un buen indicador del grado de integración de la misma (Garrard ; y otras, 2006). En lugares donde la bicicleta forma parte de las dinámicas habituales de la movilidad urbana, el uso en base al género tiende a estar más igualado que en aquellos otros donde ésta se encuentra todavía en un momento inicial de expansión (Garrard; y otras, 2012).

La mayoría de los estudios que se han ocupado de analizar las diferencias de género en el uso urbano de la bicicleta señalan la percepción del riesgo como uno de los grandes condicionantes. La creación de infraestructuras ciclistas segregadas y/o espacios de circulación que minimicen esa percepción del riesgo se propone como una de las claves para propiciar el incremento de usuarias. Existen sin embargo, otros elementos de carácter social y simbólico que intervienen de forma significativa en la generación de entornos propicios para el uso ciclista y que están estrechamente ligados a los imaginarios sociales existentes sobre mujeres y bicicletas. Dichos imaginarios, entretejidos con prácticas, discursos y experiencias cotidianas de ciclistas y del resto de transeúntes, intervienen en la construcción social de los espacios en los que la movilidad ciclista tiene lugar; espacios que a su vez propician o desincentivan el uso de la bicicleta para unos y otras. Poner estos elementos en relación con una movilidad que permita el acceso equitativo para los distintos grupos de población nos parece tarea imprescindible para un fomento real de la sostenibilidad en las ciudades.

Sevilla, caso paradigmático de explosión ciclista, ilustra un punto intermedio en el proceso de integración de la bici y los cambios en la percepción social de las mujeres que la usan. A pesar del incremento significativo de usuarios en pocos años, las considerables desproporciones de género merecen ser tenidas en cuenta a la hora de valorar el verdadero nivel de calado del fenómeno ciclista en la movilidad de la ciudadanía, así como de fomentar su uso como medio de transporte. Estas desproporciones, miradas de cerca y a través del prisma de los imaginarios sociales, nos hablan de la importancia que estos tienen en prácticas tales como la elección del atuendo y la bicicleta, de las formas de conducción, el espacio de tránsito y hasta el tipo de accesorios. La ausencia de determinados perfiles de mujeres sobre dos ruedas y el incremento de otros ilustra la superposición de nuevas y viejas representaciones, muy marcada cuando hablamos de generaciones distintas.

Las representaciones existentes sobre mujeres y bicicletas han sido controvertidas desde sus inicios, sirviendo a muy diversos intereses, desde las reivindicaciones feministas de los siglos XIX y XX a la reproducción de la hegemonía androcéntrica. Dichas representaciones resultan hoy mucho más complejas y variadas en sus referentes y significados que hace pocos años. Así, mientras que la imagen de una mujer en bicicleta sigue teniendo una componente de "exotismo", empiezan a afianzarse percepciones la suavizan. La búsqueda o preservación de la propia estética alimenta a su vez las percepciones de autonomía, libertad y modernidad que se repiten en los discursos de las ciclistas y se entretejen con las percepciones de practicidad y comodidad de las que goza la bicicleta entre sus actuales usuarios/as.

Asistimos a un proceso en el que las nuevas generaciones, como depositarias de las representaciones sociales que están emergiendo en la actualidad, jugarán un papel clave a la hora de transformar los hábitos e imaginarios sobre la movilidad y la propia ciudad. Las madres ciclistas, principales responsables de los desplazamientos asociados a la crianza, están desempeñando ya un papel relevante en este sentido.

También hemos señalado cómo los ambientes ciclistas muy masculinizados limitan el acercamiento de muchas mujeres a la bicicleta. Para la mayoría de las ciclistas sevillanas, las estéticas deportivo-competitivas resultan menos atractivas que aquellas otras de carácter urbano, más inclusivas con la variabilidad de estilos y ritmos de tránsito por el espacio urbano. 
En este sentido, el fomento del uso de la bicicleta entre las mujeres pasa por hacerlo accesible a la diversidad de ciclistas, actuales y potenciales, prescindiendo de estereotipos, generando imágenes que reflejen la heterogeneidad propia de nuestras sociedades y atendiendo de forma especial a la incorporación de aquellos perfiles con menor presencia en la movilidad ciclista. Esta atención a la pluralidad, así como a los condicionantes socioculturales que operan de forma específica sobre determinados colectivos resulta clave para cualquier medida que persiga, no solo una transición hacia modelos de movilidad más limpios, sino también un acceso equitativo a los medios de transporte necesarios para ello.

\section{Bibliografía}

ARONSON, Sidney

1952 "The sociology of the bicycle" en Social Forces, Vol. 32, núm. 3: 305-312

AYUNTAMIENTO DE SEVILLA

2006 Investigación sobre el uso de bicicletas en la ciudad de Sevilla y las demandas de los usuarios

AYUNTAMIENTO DE SEVILLA

2007 Cuantificación de bicicletas en los itinerarios de la nueva red de vías ciclistas de Sevilla AYUNTAMIENTO DE SEVILLA

2008 Desplazamientos en bicicletas en la red de vías ciclistas de Sevilla. Conteo en 42 puntos de observación. Informe de resultados

AYUNTAMIENTO DE SEVILLA

$2010 \quad$ Estudio sobre el uso de la bicicleta en la ciudad de Sevilla

AYUNTAMIENTO DE SEVILLA

2013 Eco-Contadores de la Red de Vías Ciclistas. Datos suministrados Primer Semestre 2013, Gerencia de Urbanismo

BARRERA, Begoña

2014 "Personificación e Iconografía de la mujer moderna. Sus protagonistas de principios del siglo XX en España” en Trocadero, núm. 26: 221-240

BONHAM, Jennifer; WILSON Anne.

2012 "Bicycling and the Life Course: The Start-Stop-Start Experiences of Women Cycling" en International Journal of Sustainable Transportation Vol. 6, Issue 4: 195-213

CALVO, Manuel

2013 Movilidad sostenible en nuestras ciudades. Secretariado de Publicaciones de la Universidad de Sevilla

CASTILlA, M.T; MILLÁN, J; MORENO, M; ORTEGA, P; ROMÁN, M. y VEGA, P.

2011 Patrones de movilidad en el transporte público de Andalucía. Consejería de Obras Públicas y Vivienda, Junta de Andalucía

CEBOLLADA Ángel

2006 “Aproximación a los procesos de exclusión social a partir de la relación entre el territorio y la movilidad cotidiana" en Documents d'Anàlisi Geogràfica, vol. 48: 105-121

DEL VALLE, Teresa.

1997 Andamios para una nueva ciudad. Madrid: Ed. Cátedra

DE CERTAU, Michael.

2000 La invención de lo cotidiano. México: Universidad Iberoamericana

DELGADO, Manuel.

2007 Sociedades Movedizas. Pasos hacia una antropología de las calles. Barcelona: Anagrama

EMOND, Catherine; TANG Wei; HANDY, Susan

2009 "Explaining Gender Difference in Bicycling Behavior" en Transportation Research Record: Journal of the Transportation Research Board, Vol. 2125: 16-25

ERSKINE, F.J.

2014 Damas en Bicicleta. Cómo vestir y normas de comportamiento. Impedimenta, [Orig. 1897]

GÁLVEZ, Cristina y DEL CAMPO, Alberto

2015 Etnografía de la bicicleta en Granada, Junta de Andalucía en http://hdl.handle. 
net/10433/1467

GÁLVEZ, Cristina; HUERTA, Elena y MARTÍN, Isabel

2015 "Mujeres ciudades y bicicletas. Una aproximación socio-ambiental al uso de la bicicleta como medio de transporte por parte de las mujeres en contextos urbanos andaluces" (en prensa)

GARCÍA CANCLINI, Néstor

1995 Consumidores y Ciudadanos. México: Grijalbo.

GARCÍA CANCLINI, Néstor

$2001 \quad$ Culturas híbridas: estrategias para entrar y salir de la modernidad. Buenos Aires: Paidós

GARRARD, Jan; CRAWFORD, Sharyn y HAKMAN, Natalie

2006 Revolutions for women: increasing women's participation in cycling for recreation and transport. Final report, Deakin University: Melbourne

GARRARD, J; HANDY S. Y DILL, J.

2012 "Women and cycling" en Pucher, J. y Bueheler, P (Coords.), City Cycling, pp. 211 234, Massachusetts Institute of Technology

GESOP

2011 Barómetro anual de la bicicleta: España, Informe de Resultados, Fundación ECA Bureau Veritas

HEESCH, Kristiann; SAHLQVIST, Shannon y GARRARD, Jan

2012 "Gender differences in recreational and transport cycling: a cross-sectional mixed-methods comparison of cycling patterns, motivators, and constraints" en International Journal of Behavioral Nutrition and Physical Activity, 9: 106

HERNÁNDEZ, Macarena; AIX, Francisco y HUERTA, Elena

2015 "Bicicletas como objetos y ciclistas como sujetos" (en prensa)

HUERTA, Elena y HERNÁNDEZ Macarena

2015 Etnografía de la bicicleta en Sevilla, Junta de Andalucía en http://hdl.handle.

ILÁRAZ, Imanol net/10433/1425 (18-03-2016)

2006 "Movilidad sostenible y equidad de género" en Zerbitzuan, núm. 40: 61-66

INGOLD, Tim

2000 The perception of the environment: Essays on livelihood, dwelling and skills. Londres,

JIRÓN, Paola Nueva York: Routledge

2007 "Implicancias de género en las experiencias de movilidad cotidiana urbana en Santiago de Chile "Revista Venezolana de Estudios de la Mujer vol.12 núm. 29 http://www.scielo.org. ve/scielo.php?script=sci_arttext\&pid=S1316-37012007000200011\&lng=en\&nrm=iso\&tl $\mathrm{ng}=\mathrm{es}(18-03-2016)$

JOSEPH, Isaac

1988 El transeúnte y el espacio urbano: ensayo sobre la dispersión del espacio público. Barcelona: Gedisa

LANGE Carlos

2011 "Dimensiones culturales de la movilidad urbana" en Revista INVI núm. 71, Vol. 26: 87-106

LEFEBVRE, Henri

2013 La producción del espacio. Capitán Swing, (Orig. 1975)

MACKINTOSH P, NORCLIFFE G.

2007 "Men, women and the bicycle. gender and social geography of cycling in the late nineteenth-century" en Horton D; Rosen, P. y Cox, P. (Coord.), Cycling and society, pp. 153178, Hampshire, Ashgate Publishing

MARQUÉS, Ricardo; CALVO, Manuel; HERNÁNDEZ-HERRADOR, Vicente y DEL MORAL, Leandro

2012 Investigación sobre el uso de la bicicleta en la ciudad de Sevilla, Universidad de Sevilla MARQUÉS Ricardo, CALVO, Manuel y HERNÁNDEZ-HERRADOR, Vicente.

2014 Evaluación del uso de la bicicleta en la ciudad de Sevilla, Universidad de Sevilla.

MARQUÉS, Ricardo; CALVO, Manuel y HERNÁNDEZ-HERRADOR, Vicente

2016 Análisis sobre la movilidad ciclista en Sevilla. Año 2015, Universidad de Sevilla 
MARTÍN, Isabel y JORDI, Mario

2015 Etnografía de la bicicleta en Cádiz, Junta de Andalucía http://hdl.handle.net/10433/1468 (1803-2016)

MORENO, Esperanza y QUINTERO, Victoria.

2015 Etnografía de la bicicleta en Córdoba, Junta de Andalucía, http://hdl.handle.net/10433/1563 (18-03-2016)

MORILLO TRUJILLO, Myriam Elizabeth

2014 Construyendo ciudad: un enfoque desde las subjetividades femeninas a partir de la decisión del uso de la bicicleta como medio de transporte alternativo en la ciudad de Quito.

PEÑA, Gabriela Universidad de Quito, http://repositorio.puce.edu.ec (18-03-2016)

2003 "Simmel y la escuela de Chicago: en torno a los espacios públicos en la ciudad" en Sincronía 28 http://sincronia.cucsh.udg.mx/pena03.htm (18-03-2016)

SANTA CLETA S.C.A. y ANTROPOLÓGICAS S.C.A.

2013 Prospección de género sobre movilidad en la ciudad de Sevilla, Consejería de Fomento y Vivienda, Junta de Andalucía.

SENNET, Richard

1997 Carne y piedra. El cuerpo y la ciudad en la civilización occidental. Madrid: Alianza Editorial

SGUIGLIA, Nicolás y AIX, Francisco

2015 Etnografía de la bicicleta en Málaga, Junta de Andalucía http://hdl.handle.net/10433/1535 (18-03-2016)

SIMMEL, George.

1986 El individuo y la libertad. Ensayos de crítica de la cultura. Barcelona, Península, Serie Historia, Ciencia, Sociedad

SIMPSON, C.

2001 "Respectable identities: New Zealand Nineteenth-Century New Women- on Bicycles!" en The International Journal of the History of Sport, 18: 2, 54-57

SPINNEY, Justin

2007 "Cycling the city. Non place and sensory construction of meaning in a mobile practice" en Horton D; Rosen, P. y Cox, P. (Coords.), Cycling and society, pp. 25-45 Hampshire, Ashgate Publishing

SPINNEY, Justin

2011 "A Chance to Catch a Breath: Using Mobile Video Ethnography in Cycling Research", en Mobilities, 6: 2, 161-182

WILLARD, Frances

1895 A Wheel within a Wheel. New York: Fleming H. Revell Company. Disponible https:// archive.org/details/wheelwithinwheel00williala (18-03-2016)

ZUBIAURRE, Maite

2007 "Velocipedismo sicalíptico: erotismo visual, bicicletas y sexualidad importada en la España finisecular" en Journal of Iberian an Latin American studies 13: 2-3, 217-240

\section{Webs}

http://bicicultures.org/2013/01/28/two-perspectives-on-research-in-women-cycling/ (11-03-2016)

http://www.citylab.com/commute/2014/04/there-such-thing-feminine-way-ride-bike/8886/ (14-032016)

http://www.terra.org/categorias/blog-de-un-ecologista/la-mujer-y-la-bicicleta (14-03-2016)

http://xroads.virginia.edu/ ug02/hendrick/women.html (11-03-2016)

http://madridcyclechic.blogspot.com.es/p/madrid-cycle-chic-manifesto_22.html (14-03-2016)

\section{3}

